\title{
Histomorphological Profile of Colonoscopic Biopsies - A Two Year Study in a Tertiary Care Hospital in South India
}

\author{
Dr. Megha Shukla Pandey ${ }^{1}$, Dr. Ashish Pandey ${ }^{2}$, Dr. V. D. Dombale ${ }^{3}$ \\ ${ }^{1}$ Assistant Professor, Department of Pathology, Chirayu Medical College \& Hospital, Bhopal \\ ${ }^{2}$ Assistant Professor, Department of Pathology, Chirayu Medical College \& Hospital, Bhopal
}

${ }^{3}$ Professor \& H.O.D, Department of Pathology, S. Nijalingappa Medical College \& Hospital, Bagalkot

\begin{abstract}
Background: The Colonoscopy with accompanying mucosal biopsy is the prime diagnostic tool in the workup of patients with different neoplastic as well as non-neoplastic lesions of colon \& rectum. The objectives of this study were to study the spectrum of lesions in colon \& rectum on colonoscopic biopsies, to find age \& sex distribution of these lesions \& to correlate them with presenting complaints \& anatomical site. Methods: The study included colonoscopic biopsies of colon \& rectum from patients attending the department of surgery at SNMC \& Hanagal Shri Kumareshwar Hospital \& department of gastroenterology at Kerudi Hospital \& Research Centre, Bagalkot from January 2012 to December 2013. There were 108 colonoscopic biopsies during this period, among which 105 biopsies were included in the study. The histological classification of these lesions was based on World Health Organization (WHO). Results: Out of total 108 biopsies, 79 were non-neoplastic lesions, 26 were neoplastic lesions \& 3 were inadequate biopsies for accurate interpretation. Most patients presented in the age group of 21-30 years with a male to female ratio of 1.76:1. The most common presenting complaint for both non-neoplastic \& neoplastic lesions was diarrhoea. Of all the lesions maximum were non-neoplastic lesions, among which chronic non-specific colitis was commonest. In the neoplastic lesions, classical adenocarcinoma was the commonest subtype encountered. Interpretation \& Conclusion: Majority of the lesions of colon and rectum were non-neoplastic \& comprised of chronic non-specific colitis, acute on chronic non-specific colitis, ulcerative colitis, tuberculosis, Hirschsprung's disease, proctocolitis\&proctitis. All these were more common in males \& in the age group of 21-30 years and commonly presented with diarrhoea.The most common neoplasm was classical adenocarcinoma, which was found in patients above 40 years of age. There were two cases each of mucin secreting adenocarcinoma \& signet ring cell carcinoma, which were seen in patients below 40 years of age.
\end{abstract}

Keywords: Colonoscopy; Ulcerative colitis; Chronic non-specific colitis; Tuberculosis; Hirschsprung's disease; Adenocarcinoma

\section{Introduction}

India is a vast country with a multi-linguistic population of differing race, genetic setup, culture and dietary habits. Such diversity is also seen in the clinicopathological spectrum of colorectal lesions. ${ }^{[1]}$

Disorders of colon account for a large portion of human diseases. Colon is the host to primary neoplasm more than any other organ in the body. Colonic conditions like infections, idiopathic inflammatory diseases, polyps, motility disorders and colorectal tumours are the important lesions which often require colonoscopic biopsy for their conclusive diagnosis. ${ }^{[2]}$

The colonoscope is used to visualize the mucosa of the rectum, entire colon and terminal ileum to screen the intestinal abnormalities and to get biopsy for the definitive diagnosis. $^{[3]}$

Colonic tuberculosis is rising in general and particularly in patients with AIDS. ${ }^{[4]}$

In geographical regions where both Crohn's colitis and tuberculosis are prevalent, the differential diagnosis of the granulomatousileocolitis poses a challenge.Endoscopic mucosal biopsy specimens obtained through fiberopticsigmoidoscopes or colonoscopes from rectum, different areas of colon, ileocaecal valveand terminal ileum provides the possibility of histological conformation of the diagnosis of tuberculousileocolitis (TEC) or Crohn's disease in suspected early cases. ${ }^{[5]}$

Colonoscopy has assumed a pivotal role in the diagnosis and management of patients with Inflammatory bowel disease (IBD). ${ }^{[6]}$

Congenital disorder i.e. Hirschsprung's disease is common in newborns where suction biopsy sampling of mucosa and submucosa is considered the method of choice for diagnosis. $^{[7]}$

Recently with the development of flexible fibre opticsigmoidoscopy and colonoscopy the clinical management of colorectal diseases has much been revolutionized. The procedure of colonoscopy is relatively safe, with low incidence of serious complications like perforation, hemorrhage, cardiopulmonary arrest or sepsis and is becoming important clinically because of more widespread use of screening colonoscopy for colorectal cancer, application of therapeutic colonoscopy (colonoscopic polypectomy) \& exciting new technical improvements. $^{[8]}$

\section{Materials \& Methods}

The present study included colonoscopic biopsies of colon and rectum from patients attending the department of surgery, at S. Nijalingappa Medical College 


\section{International Journal of Science and Research (IJSR) \\ ISSN (Online): 2319-7064}

Index Copernicus Value (2013): 6.14 | Impact Factor (2014): 5.611

\&HanagalShriKumareshwar Hospital \& Research Centre and department of gasto-enterologyat Kerudi Hospital \& Research centre, Bagalkot during the period from January 2012 to December 2013. Brief clinical data were noted from the case records, which included the age $\&$ sex of the patient, presenting complaints, clinical and colonoscopic diagnosis.

\section{Inclusion Criteria}

- Patients belonging to all age groups.

- Presenting with bleeding PR, constipation, diarrhoea, abdominal pain \& anaemia.

- Lesions of colon and rectum.

\section{Exclusion Criteria}

- Apparently healthy individuals.

- Patients presenting with lesions in small intestine and anal canal.

- Inadequate biopsies in terms of no mucosal glands, only fibro-collagenous tissue, etc.

A minimum of 3-5 bits were studied in each case and the colonoscopic biopsy specimens thus obtained were fixed in $10 \%$ formalin. Before processing, the samples were stained with eosin for their better and complete visualization and wrapped in a tissue paper to prevent dispersion and actual loss of tissue. All the bits were embedded together for ideal visualization. Then, sections 4-6 microns were stained routinely with Haematoxylin \& Eosin and special stains were used wherever necessary.

\section{Results}

A total of 108 colonoscopic biopsies were examined during the study period. Biopsies were obtained from different sites, in maximum number of cases they were obtained from multiple sites (45.7\%). The study included 67 males and 38 females with male to female ratio of $1.76: 1$ and 3 inadequate biopsies were excluded from the study. Biopsies were performed on patients of all age groups, the youngest being a 5 days old neonate and oldest being a 78 year old male. Among 105 cases, patients presented with varying clinical features, in decreasing order of frequency these were diarrhoea (58 cases), bleeding (43 cases), abdominal pain (21 cases), constipation (11 cases) and anaemia (06 cases). The colonoscopic biopsies were divided as non-neoplastic, neoplastic and inadequate for an accurate interpretation as shown in table (I)

Table 3: Age distribution in non-neoplastic lesions

\begin{tabular}{|c|c|c|c|c|c|c|c|c|}
\hline Age group & $\begin{array}{c}\text { Acute non-sp } \\
\text { colitis }\end{array}$ & $\begin{array}{c}\text { Chronic non- } \\
\text { sp colitis }\end{array}$ & $\begin{array}{c}\text { Acute on chr } \\
\text { non-sp colitis }\end{array}$ & Tuberculosis & $\begin{array}{c}\text { Ulcerative } \\
\text { colitis }\end{array}$ & $\begin{array}{c}\text { Hirsch } \\
\text { disease }\end{array}$ & Proctocolitis & Proctitis \\
\hline $0-10$ & & - & - & - & - & $6(100 \%)$ & - & - \\
\hline $11-20$ & & $6(13.95 \%)$ & $3(21.42 \%)$ & $1(50 \%)$ & - & - & - & - \\
\hline $21-30$ & $1(33.33 \%)$ & $13(30.23 \%)$ & $4(28.57 \%)$ & - & $3(33.33 \%)$ & - & $1(100 \%)$ & - \\
\hline $31-40$ & $2(66.66 \%)$ & $10(23.25 \%)$ & $2(14.28 \%)$ & - & $2(22.22 \%)$ & - & - & - \\
\hline $41-50$ & & $5(11.62 \%)$ & $2(14.28 \%)$ & - & $3(33.33 \%)$ & - & - & $1(100 \%)$ \\
\hline $51-60$ & & $5(11.62 \%)$ & $1(7.14 \%)$ & $1(50 \%)$ & $1(11.11 \%)$ & - & - & - \\
\hline $61-70$ & & $2(4.65 \%)$ & $1(7.14 \%)$ & - & - & - & - & - \\
\hline $71-80$ & & 2 & $1(7.14 \%)$ & - & - & - & - & - \\
\hline $81-90$ & & - & - & - & - & - & - & - \\
\hline $91-100$ & & - & - & - & - & - & - & - \\
\hline Total & 03 & 43 & 14 & 02 & 09 & 06 & 01 & 01 \\
\hline
\end{tabular}


International Journal of Science and Research (IJSR)

ISSN (Online): 2319-7064

Index Copernicus Value (2013): 6.14 | Impact Factor (2014): 5.611

Table 4: Malignant neoplastic lesions

\begin{tabular}{|c|c|c|}
\hline Sr.no & Lesion & No.of cases \\
\hline 1. & Adenocarcinoma & $\mathbf{1 7}(\mathbf{8 2 \%})$ \\
\hline 2. & Mucinsecreting adenocarcinoma & $02(9 \%)$ \\
\hline 3. & Signet ring cell carcinoma & $02(9 \%)$ \\
\hline & Total & 21 \\
\hline
\end{tabular}

Table 5: Age \& Sex distribution of malignant lesions

\begin{tabular}{|c|c|c|c|c|c|c|}
\hline \multirow{2}{*}{ Age group } & \multicolumn{2}{|c|}{ Adenoca } & \multicolumn{2}{c|}{ Mucin sec ca } & \multicolumn{2}{c|}{ Signet ring cell ca } \\
\cline { 2 - 7 } & $M$ & $F$ & $M$ & $F$ & $M$ & $F$ \\
\hline $0-10$ & - & - & - & - & - & - \\
\hline $11-20$ & - & - & - & - & - & - \\
\hline $21-30$ & - & - & 01 & 01 & 00 & 01 \\
\hline $31-40$ & 01 & 02 & - & - & - & - \\
\hline $41-50$ & 03 & 01 & - & - & 00 & 01 \\
\hline $51-60$ & 03 & 01 & - & - & - & - \\
\hline $61-70$ & 04 & 01 & - & - & - & - \\
\hline $71-80$ & 00 & 01 & - & - & - & - \\
\hline $81-90$ & - & - & - & - & - & - \\
\hline $91-100$ & - & - & - & - & - & - \\
\hline Total & \multicolumn{2}{|c|}{17} & \multicolumn{2}{|c}{02} & \multicolumn{2}{|c}{02} \\
\hline
\end{tabular}

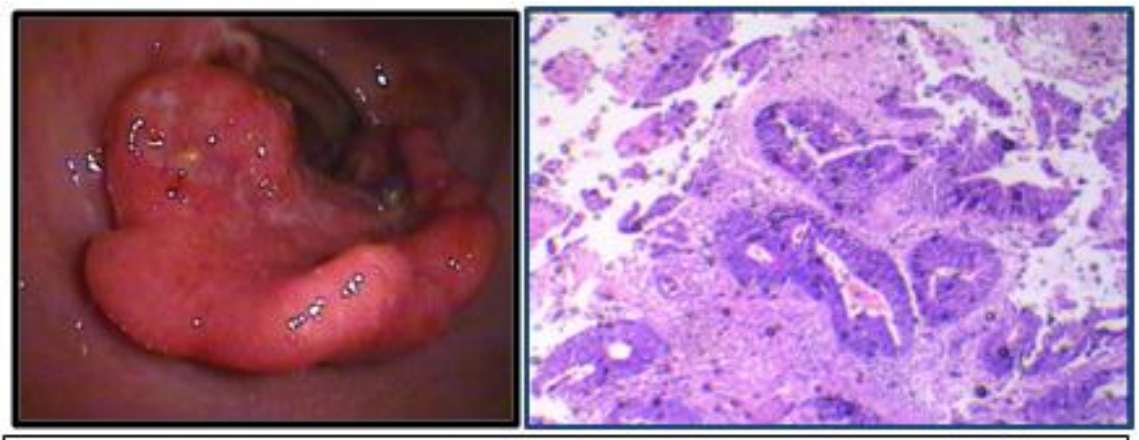

Figure 1: a) Colonoscope - Ulceroproliferative growth- rectum b) Adenocarcinoma-rectum. H\&E $100 \mathrm{X}$

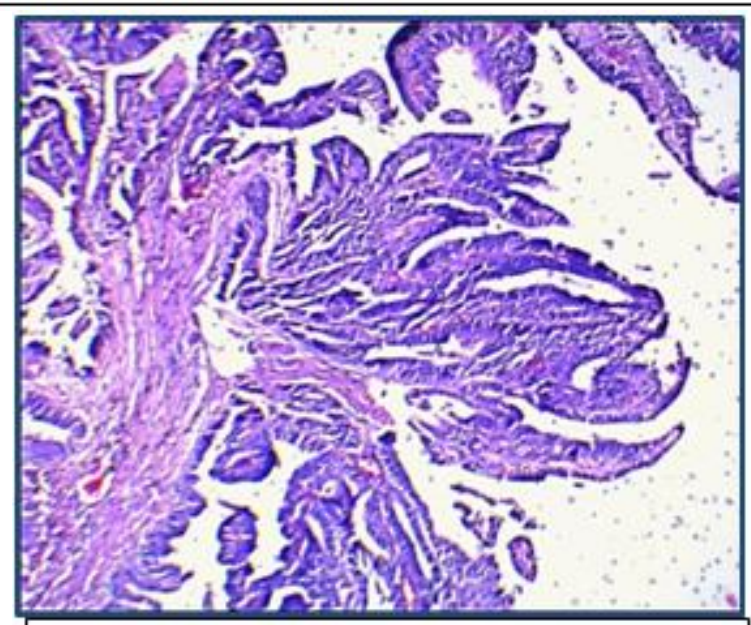

Figure 2: Papillary a denocarcinoma-Sigmoid colon. H\&E 40X

Volume 5 Issue 2, February 2016 www.ijsr.net 
International Journal of Science and Research (IJSR)

ISSN (Online): 2319-7064

Index Copernicus Value (2013): 6.14 | Impact Factor (2014): 5.611

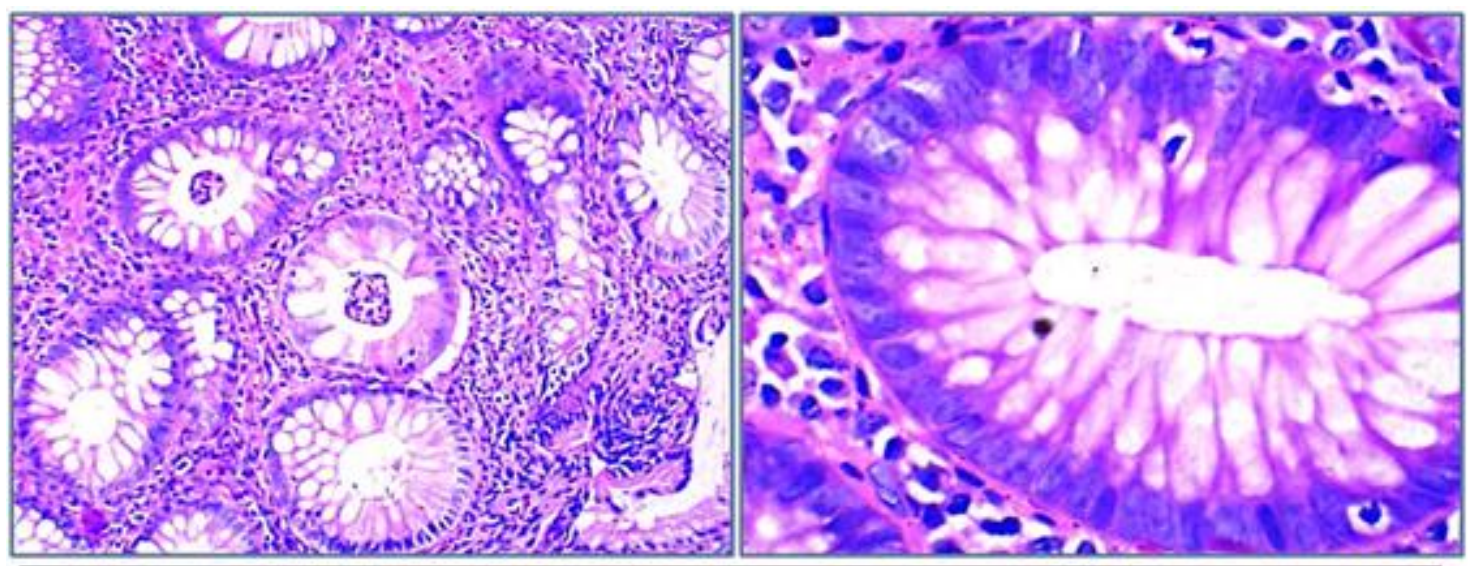

Figure 3: a) Crypt abscess with chronic inflammatory infiltrate in lamina propria. H\&E 100X b) Crypt lining showing neutrophilic infiltration. $H \& E$ $400 \mathrm{X}$

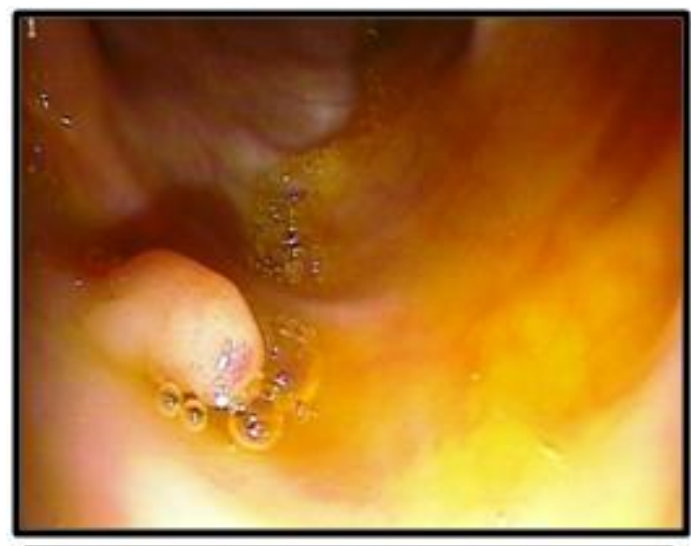

Figure 4: Rectal polyp

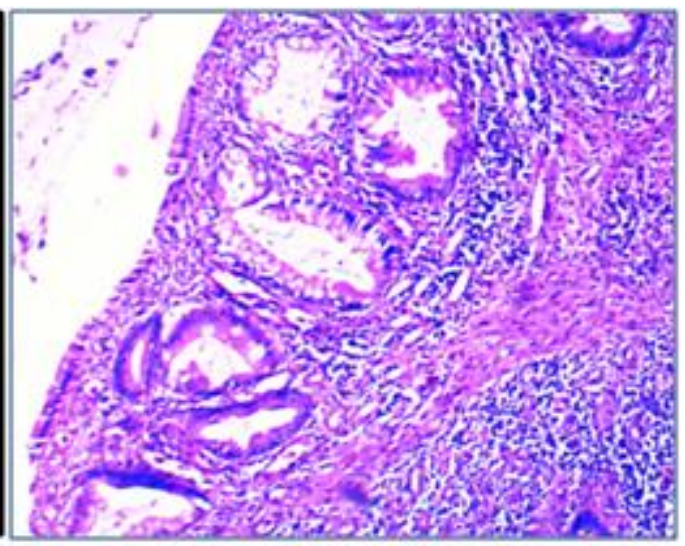

Figure 5: Juvenile rectal polyp - showing columnar epithelial lining. H\&E 40X

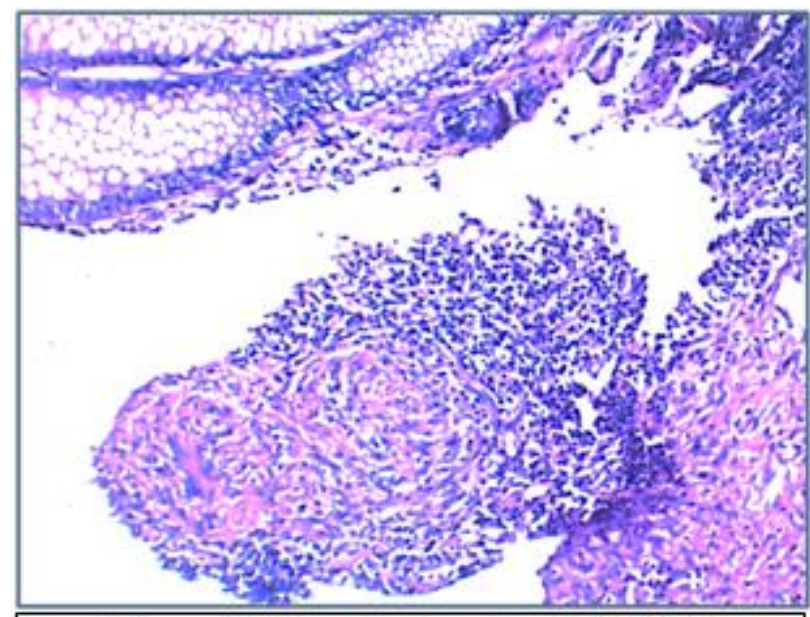

Figure 6: Tuberculosis - colon H\&E 100X

Volume 5 Issue 2, February 2016 www.ijsr.net 


\section{International Journal of Science and Research (IJSR) ISSN (Online): 2319-7064}

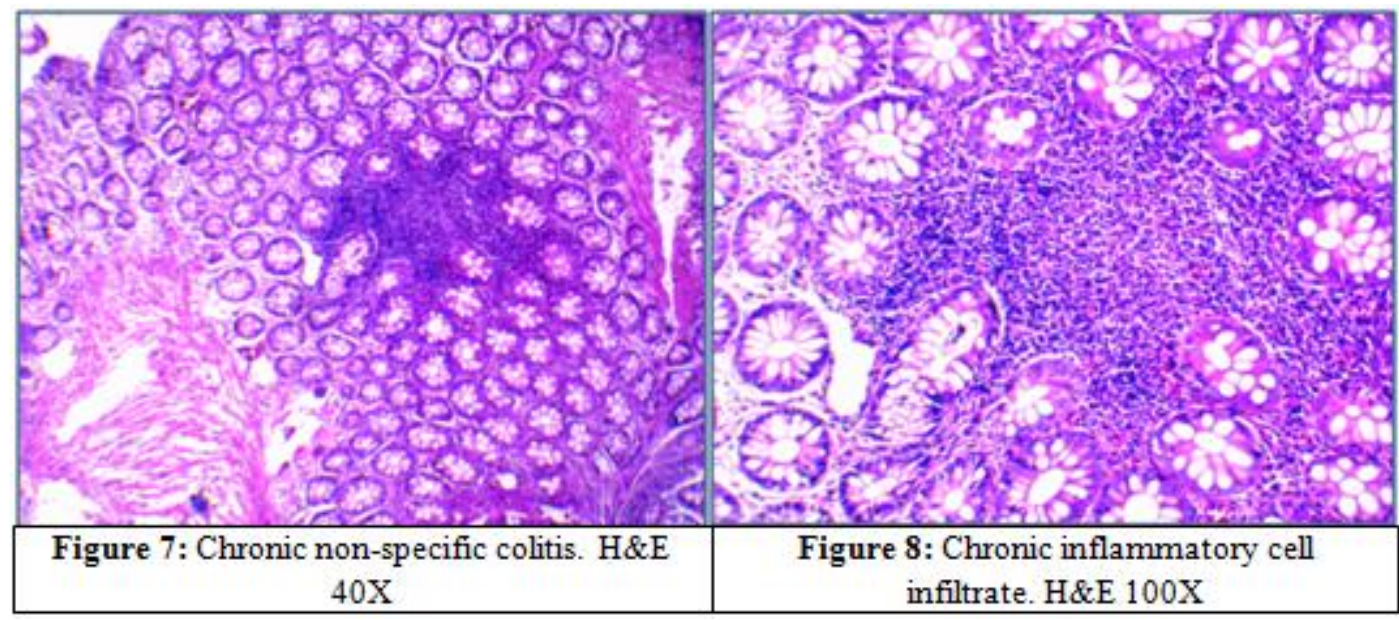

\section{Discussion}

Endoscopy is a crucial tool in the diagnosis and management of various lesions of colon and rectum. Recent widespread use of flexible endoscope has produced a dramatic expansion of our knowledge of the pathogenesis and evolution of disease processes affecting the gastrointestinal tract. Symptomatology of colorectal lesions is very nonspecific and hence is the central role played by colonoscopy in the early detection of colonic lesions.

Chronic non-specific colitis comprised the maximum number of cases in our study however, definitive etiologic factor could not be identified in most of the cases, which correlates with the findings drawn by Deshpande $\mathrm{V}$ et al. ${ }^{[9]}$

Visual inspection of the colon and in certain cases, the terminal ileum, is a crucial component of the workup of a patient with suspected IBD. The colonoscopic examination with accompanying biopsy specimens can often establish the diagnosis, determine the extent and severity of IBD, and establish the presence of dysplasia during surveillance to reduce the risk of colorectal cancer. ${ }^{[6]}$

The incidence and prevalence of Ulcerative colitis in the Indian subcontinent is on the rise and the disease is characterised by remissions and relapses ${ }^{[10]}$ But its accurate diagnosis still remains uncommon despite of greater awareness of the disease and better diagnostic facilities that distinguish ulcerative colitis from other types of colitis. It is a challenging clinical entity which requires early diagnosis, thereby to avoid severity of disease. ${ }^{[1]}$

Similar to previous studies by D Badmapriyaet al and Soodet al present study also observed male preponderance in cases of ulcerative colitis. Disease prevalence was high in patients between 21 to 30 years and 41 to 50 years with diarrhoea as commonest presenting complaint. These findings contrasted observations of D Badamapriya et al and Sood et al where bleeding per rectum was commonest symptom. ${ }^{[11,12]}$ Most of our cases had pancolitis similar to findings of Sivaram $\mathrm{G}$ et al. ${ }^{[13]}$

All the six cases of mechanical disorder were of Hirschsprung's disease. Maximum number of these cases were in the neo-natal period which is in concordance with previous studies .However, female preponderance was observed in present study which contrasted findings of Anupamaet $a l$ and Jung et al who observed male preponderance ${ }^{[14,15]}$

India carries almost one quarter of the world's total tuberculosis burden. It is a biggest health crisis confronting India. Present study encountered 2 cases of intestinal tuberculosis with equal sex incidence and mean age of presentation of 63 years, which mirrors the findings of Leung VKS et al. ${ }^{[16]}$

Screening for colorectal cancer by colonoscopy with removal of precancerous lesions is a powerful and effective approach for reducing colorectal cancer incidence and mortality, therefore it is now considered as gold standard for the diagnosis of colorectal cancer. ${ }^{[17]}$ Amongst 21 colonoscopic biopsies diagnosed as malignant lesions, 17 were of adenocarcinoma, 2 of mucin secreting carcinoma and remaining 2 of signet ring cell carcinoma. These lesions showed male preponderance and majority of the patients were above 40 years similar to the observations of Phillipoet $a l .{ }^{[18]}$ In the present study, the patients less than 40 years of age tended to have poor prognostic tumors such as mucinous and signet ring cell carcinoma, this finding concurs with previous studies. ${ }^{[19]}$

Bleeding is an index symptom in early stage colorectal cancer, therefore it merits an urgent and full investigation, as it is a diagnostic challenge to distinguish a benign condition from a serious underlying colorectal disease on the basis of bleeding alone. Rectal bleeding was the commonest presenting symptom for malignant lesions in the present study which is in agreement with studies of Yawe KTet al ${ }^{[20]}$ and Saidi HS et al. ${ }^{[21]}$

Majority of the neoplastic lesions were left sided, especially involving rectum followed by recto-sigmoid and sigmoid colon, similar to the findings made by Gurjeetet al. ${ }^{[22]}$

There is no doubt that fibreoptic colonoscopy increases diagnostic accuracy in large bowel diseases \& is especially helpful in cases where radiology is either negative or equivocal. ${ }^{[23]}$ Colonoscopy and colonoscopic biopsy examinations are now performed not only for the diagnosis of diseases but also for monitoring the course of wide variety of conditions and for the early detection of complications of colonic lesions. As a consequence, the

\section{Volume 5 Issue 2, February 2016}




\section{International Journal of Science and Research (IJSR) \\ ISSN (Online): 2319-7064}

Index Copernicus Value (2013): 6.14 | Impact Factor (2014): 5.611

reasons for obtaining mucosal biopsy material have increased, and no longer are they performed to simply identify neoplasms. Thus colonoscopy with biopsy plays a significant role in reducing morbidity \& mortality in patients with colorectal lesions. ${ }^{[24]}$

\section{Conclusion}

The histomorphological profile of colorectal biopsies have a wide spectrum, ranging from infectious conditions, inflammatory disorders, precancerous lesions to colorectal malignancies. Inflammatory pathologies are found to affect the colorectal region most frequently. Therefore colorectal lesions need an accurate diagnostic approach, wherein interpretation of colorectal mucosal biopsies by histopathologists has now taken a cornerstone place in the workup and management of patients with colorectal lesions.

\section{References}

[1] Sanjay Bandyopadhyay. Crohn's disease: The Indian Perspective. Medicine update 2012; 22:419-425

[2] Qayyum A, Sawan AS. Profile of colonic biopsies in King Abdul Aziz University Hospital, Jeddah. J Park Med Assoc 2009 Sep;59(9):608-11.

[3] Cherneck and Berger. In: laboratory test and diagnostic procedure. $5^{\text {th }}$ edn; 2008:65-66.

[4] Shah S, Thomas V, Mathan M, et al. Colonoscopic study of 50 patients with colonic tuberculosis. Gut 1992; 33:347-51.

[5] Pulimood AB, Ramakrishna BS, Kurian G, Peter S, Patra S, Mathan MM. Endoscopic mucosal biopsies are useful in distinguishing granulomatous colitis due to Crohn's disease from tuberculosis. Gut 1999;45:537541.

[6] Chutkan RK, Waye JD. Endoscopy in Inflammatory bowel disease. In: KirsnerJB,ed. Inflammatory bowel disease. $5^{\text {th }}$ ed. Baltimare : Williams \& Wilkins:2000:453-777

[7] Rosai J. In: Rosai and Ackerman's Surgical $\begin{array}{lll}\text { Pathological } \quad 9^{\text {th }} \text { edn, } & \operatorname{vol}(1): & \text { Elsevier }\end{array}$ publication;2001:777-816.

[8] Cappell MS, Friedel D. The role of sigmoidoscopy and colonoscopy in the diagnosis and management of lower gastrointestinal disorders: endoscopic findings, therapy and complication. Med Clin North Am 2002 Nov; $86: 1253-88$

[9] Deshpande V, Hsu M, Kumarasinghe MP, et al. The clinical significance of incidental chronic colitis: a study of 17 cases. Am J SurgPathol 2010; 34(4):463-9.

[10] Sheenam Azad, NeenaSood, AjitSood. Biological and Histological Parameters as Predictors of Relapse in Ulcerative colitis: A prospective study. Saudi J Gastroenteral 2011 May-Jan;17(3): 194-198.

[11] D. Badmapriya, Kumar V.S. Profile of Ulcerative colitis in South India Region: Karaikal. IJPBS 2011;1(2):47-51

[12] Sood A, Vandana M, et al. Profile of Ulcerative Colitis in a North India Hospital. Journal of Indian Academy of Clinical Medicine 1998; 5(2):124-128.

[13] Sivaram G, Santosh K, et al. The epidemiology and prevalence of Ulcerative Colitis in the South of India. Open Journal of Immunology 2012; 2(4):144-148.
[14] Anupama B, Zheng S, Xiao X. Ten year experience in the management of total colonic aganglionosis. $\mathrm{J}$ PediatrSurg 2007;42(10):160-66.

[15]Jung PM. Hirschsprung's disease: one surgeon's experience in one institution. $\mathrm{J}$ PediatrSurg 1995;30(5):646-51.

[16]Leung VKS, Law ST, Lam CW, et al. Intestinal tuberculosis in a regional hospital in Hong Kong: a 10 year experience. Hong Kong Med J 2006;12:264-71.

[17] Betes M, Munoz-Navas MA, Dugue JM, et al. Use of colonoscopy as a primary screening test for colorectal cancer in average risk people. Am J Gastroenterol 2013;98:2648-54.

[18] Phillipo L C, Mabulla D M, Joseph BM, et al. Clinicopathological patterns and challenges of management of colorectal cancer in a resource-limited setting: a Tanzanian experience World Journal of Surgical Oncology 2013;11:88-95.

[19]Fazeli MS, Adel MG, Lebaschi AH. Colorectal carcinoma: a retrospective, descriptive study of age, gender, subsite, stage and differentiation in Iran from 1995 to 2001 as observed in Tehran University. Dis Colon Rectum 2007;50:990-95.

[20] Yawe KT, Bakeri AA, Pindiga UH, et al. Clinicopathological pattern and challenges in the management of colorectal cancer in sub-saharan Africa. J Chinese Clin Med 2007;2:688-95.

[21] Saidi HS, Karuri D, Nyaim EO: Correlation of clinical data, anatomical site and discuss stage in colorectal cancer. East Afr Med J 2008; 85:259-62.

[22] Gurjeet K, Abdelhafid M, et al. Mismatch repair genes expression defects \& association with clinicopathological characteristics in colorectal carcinoma. Indian J Med Res 2011;134(2):186-192.

[23] Teague RH, Salman PR, Read AE. Fibreoptic examination of the colon: a review of 255 cases. Gut 1973;14:139-142.

[24] Winawer SJ, Zauber AG, Ho MN, et al. Prevention of colorectal cancer by colonoscopic polypectomy. The National Polyp Study Work group. N Engl J Med 1993; 3291977-1981. 1981. 